\title{
Purification by Automatic Gas Chromatography
}

\author{
Milton Tenenbaum and Frank L. Howard
}

(February 15, 1962)

\begin{abstract}
A completely automatic apparatus has been developed for the preparative-scale purification of compounds by gas-liquid chromatography. A clock timer periodically activates a pump that injects a sample into the column. The recording potentiometer on which the chromatogram is traced has a switch mounted at the upper margin. Collection of the purified main component occurs when the recorder pen goes to the end of the scale and trips the switch. The sensitivity of the detector bridge circuit is adjusted so that only the trace caused by the major component will activate the collection process.

Toluene, ethylbenzene, and mesitylene were purified with the apparatus. Best results were obtained with toluene. In one pass through the apparatus, 92 percent of the impurities were removed from the toluene and the purified product was collected at a rate of $25 \mathrm{ml}$ of liquid per day.
\end{abstract}

\section{Introduction}

In recent years, several reports $[1,2,3,4]^{1}$ have been published describing automatically controlled apparatus for the preparative-scale purification of materials by gas-liquid partition chromatography. The basic design of Ambrose and Collerson [1] is typical. A timer and a master circuit automatically control the introduction of the sample and the collection of product according to a preset time program. These devices generally contain a rather complex electronic controller and require that the preset program remain synchronized during unattended periods. Thus, changes in operating conditions such as, the temperature of the column or flow rate of the carrier gas, can cause the sample input cycle to become out of phase with the collection cycle and result in contamination of the product.

A completely automatic preparative-scale apparatus has been developed in these laboratories to augment other separation methods for the isolation of highly purified compounds. This apparatus operates in such a way that controlled aliquots of the sample are introduced according to a preset timed cycle while collection of product is governed only by the trace on the recorder, not by a timing mechanism. The sample is injected automatically with a pump activated by a clock timer. Automatic collection is accomplished with solenoid valves activated by a microswitch mounted at the margin of the recorder and collection occurs only when the recorder pen is at the top of the scale. No difficulty has been experienced due to base line drift of the recorder during weeks of continuous use. The apparatus is relatively easy to construct and requires only simple electrical controls. When used in conjunction with a column of adequate efficiency it is possible to obtain a high degree of purification at reasonably fast collection rates.

${ }_{1}$ Figures in brackets indicate the literature references at the end of this paper.

\section{Apparatus}

\subsection{Sample Introduction}

A microbellows pump (Research Appliance Co., Pittsburgh, Pa.) $)^{2}$ is used to introduce liquid samples into the system. The amount of liquid that can be delivered per stroke by this pump may be varied from $0.05 \mathrm{ml}$ to $1.0 \mathrm{ml}$; for amounts greater than $1 \mathrm{ml}$, one must introduce samples by two or more strokes.

several components of the apparatus used are denoted by name of manufacturer to avoid detailed descriptions. This is not intended to imply that these are preferred; suitable products made by other manufacturers may serve as well.

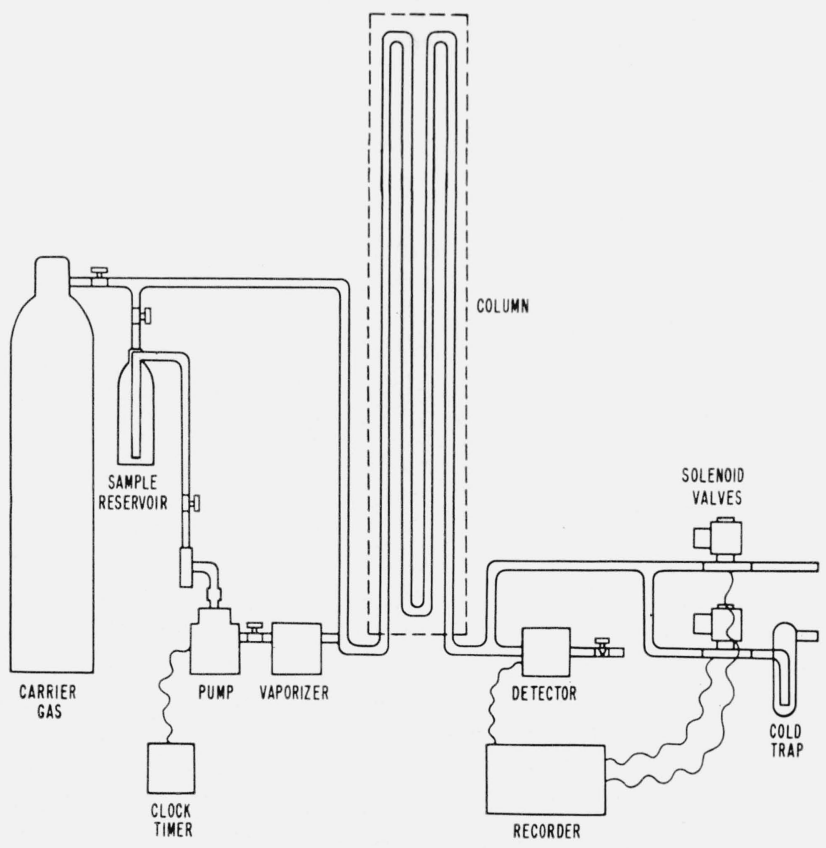

Figure 1. Diagram of apparatus. 
A cam timer driven by a clock motor activates the pump; it is deactivated by a locking relay circuit which is monitored by a microswitch located on the pump shaft. Since the helium carrier gas pressures in the input side of the system are often about 60 psig, a closed reservoir is used to contain the sample to eliminate leakage past the ball check valves in the pump. The reservoir is a steel cylinder connected to the carrier gas line so that an equalizing back pressure is maintained above the liquid. The valve above the cylinder is opened momentarily and then closed after the pressure has built up. Upon leaving the pump, the sample is vaporized in a flash evaporator. The evaporator was constructed from a brass block and is heated with a cartridge heater. A block diagram of the apparatus is given in figure 1

\subsection{Column}

The column used in the purification of toluene, ethylbenzene, and mesitylene consists of four $7.5-\mathrm{ft}$ lengths of 0.5 -in. i.d. straight copper tubing connected in series to give a column $30 \mathrm{ft}$ long. There are no constrictions at the connecting points between the lengths of tubing. The ends of the tubes were hard soldered together with very short connections between them. The tubing was filled with 100 to 120 mesh firebrick coated with 7 percent polyethylene glycol of average molecular weight 1,000.

The packed tubes were inserted in a brass tube ( 3 in. o.d. by $8 \mathrm{ft}$ ) which was connected to a liquid boiler at the bottom and a condenser at the top, the outside of the brass tube was wrapped with heating tape. This arrangement makes possible uniform heating of the columns but is not convenient when one wishes to make frequent changes in temperature since it requires draining and refilling of the boiler with another liquid of the desired boiling point. For the experiments in this report water was used as the boiler liquid.

\subsection{Detector and Collection}

The detector is a hot wire thermal conductivity unit operated with a d-c power supply (TRIIB) and 9999C, Gow Mac Co., Madison, N.J.). Flow of gas through the detector is controlled with a small needle valve. The valve is adjusted so that about one percent of the total effluent from the column passes through the detector and the remainder of the effluent stream is carried to two solenoid valves (S90A140 Ct and S90D104 Ct, Hoke Inc., Cresshill, N.J.). These solenoid valves are controlled by a microswitch (Minneapolis Honeywell No. ISM23) mounted on a Brown 1-mv recording potentiometer. When elution of the major component causes the recorder pen carrier to press on the microswitch, the solenoid valves are activated through a relay so that the purified major component is collected by diversion of the gas stream into a cold trap connected to the exit of the normally closed valve. When the recorder pen is below the activating switch, the carrier gas stream containing components to be rejected is vented to the atmosphere through the normally open solenoid valve.

\section{Experimental Procedure}

The procedure used to operate the system begins with selection of the appropriate chromatographic column, column temperature, and gas flow rate for the separation which is planned. Experiments are made to determine the time that will be required for each cycle, the sensitivity setting of the detector which will rermit only the major component peak to go to the top of the scale, and the maximum quantity of sample which may be processed without overloading the column. The apparatus is then run continuously until the desired quantity of purified material is collected. Figure 2 is a portion of the recorder trace during purification of toluene.

Reagent grade toluene, ethylbenzene, and mesitylene obtained from Eastman Kodak Co. were used as starting materials. The purities of the first two compounds were determined by the freezing point method $[5,6,7]$ before and after purification. The analyses indicated that before purification the toluene was 99.4 mole percent and the ethylbenzene 99.1 mole percent pure. Freezing point analyses were not made on mesitylene because a sufficient quantity of purified product $(50 \mathrm{ml})$ was not collected.

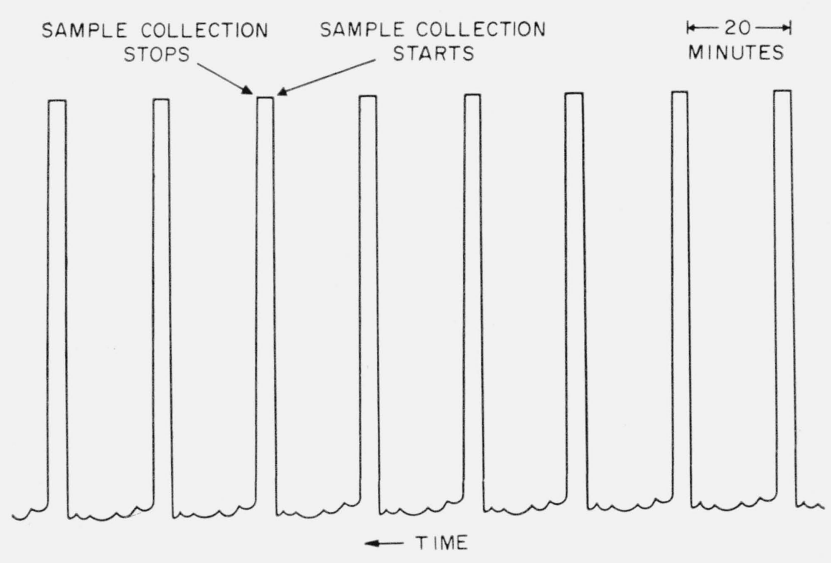

Figure 2. Portion of chromatogram from purification of toluene.

\subsection{Purification of Toluene}

The reservoir was filled with $100 \mathrm{ml}$ of toluene. The timer and pump were adjusted so that $0.44 \mathrm{ml}$ of the toluene was injected into the column every $20 \mathrm{~min}$. The column temperature was set at $100^{\circ} \mathrm{C}$ and the helium carrier gas pressure was 50 psi. A trap cooled with dry ice was used to condense and recover the purified sample. About 80 percent of the material processed was collected as purified product in the trap during 3.2 days. Figure 3 shows the cryoscopic analyses of the toluene before and after purification by this method. Melting curves were used because toluene tends to supercool excessively. The analyses indicated that 92 percent of the total impurity was removed to give a product 
of 99.95 mole percent tolvene. Chromatographic analyses of the product and starting material are shown in figure 4 . No peaks other than the major component were observed in the purified product. The chromatographic analyses were made with a Perkin-Elmer vapor fractometer, model 154, using a 150-ft polypropylene glycol Golay capillary column and a hydrogen flame ionization detector set at maximum sensitivity.

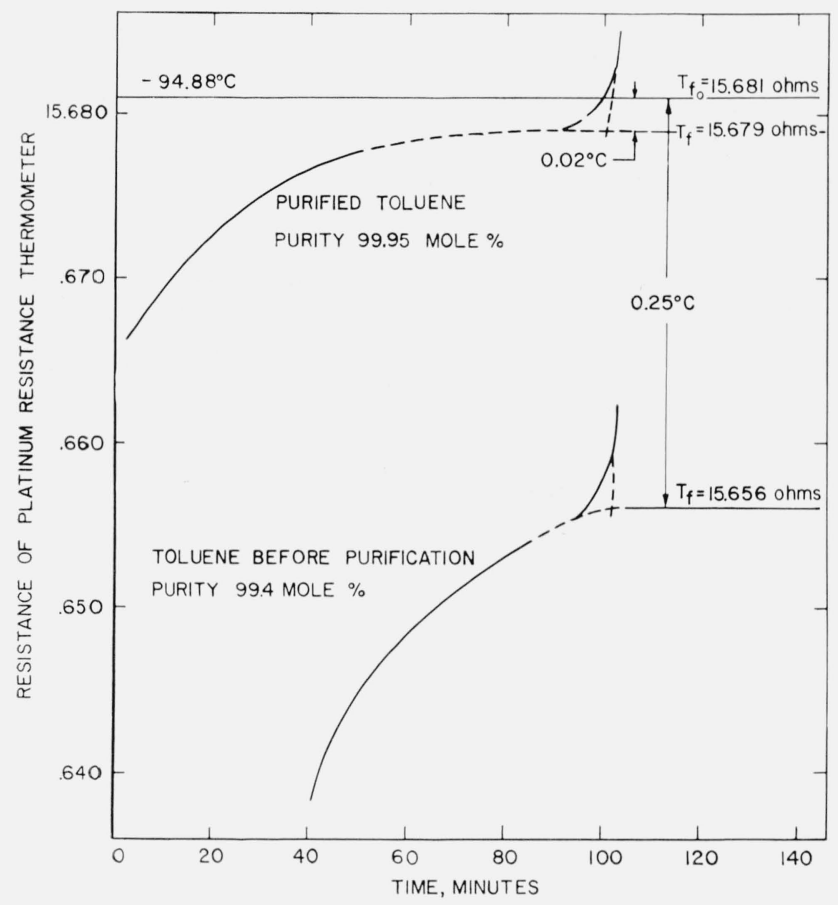

Figure 3. Melting curves of toluene before and after purification by gas chromatography.

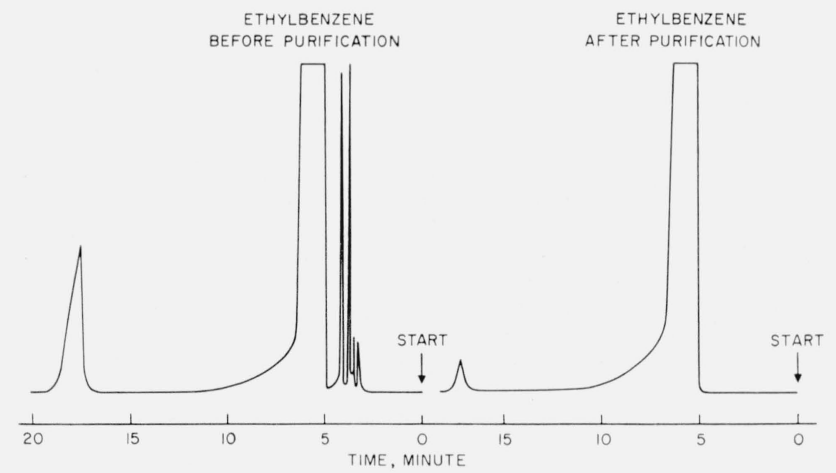

Figure 4. Chromatographic analyses of toluene before and after purification by gas chromatography.

$$
\begin{aligned}
& \text { Detector-Hydrogen flame ionization } \\
& \text { Sample size }-0.2 \text { microliters } \\
& \text { Stream split }-1 / 300 \\
& \text { Temperature }-100^{\circ} \mathrm{C} \\
& \text { Column }-150 \mathrm{ft} \times 0.01 \mathrm{in} \text {. } \\
& \text { polypropylene } \\
& \text { Flow rate } \quad-0.4 \mathrm{~cm}^{3} / \mathrm{min} \\
& \text { Pressure -15 psi } \\
& \text { Chart speed }-90 \mathrm{in} . / \mathrm{hr} \\
& \text { Attenuation }-\times 1
\end{aligned}
$$

\subsection{Purification of Ethylbenzene}

A charge of $100 \mathrm{ml}$ of ethylbenzene was processed in a manner similar to that described for toluene. In this case the rate of sample introduction was $0.25 \mathrm{ml}$ every $20 \mathrm{~min}$. The column temperature was $100{ }^{\circ} \mathrm{C}$ and the carrier gas pressure 70 psi. After 5.5 days, $70 \mathrm{ml}$ of purified ethylbenzene was collected in the cold trap. Cryoscopic analyses (fig. 5) indicated that the purity was raised from 99.1 mole percent to 99.8 mole percent so that 76 percent of the impurities were removed. A large part of the decrease in separating efficiency from that observed with toluene appears to be due to an impurity shown in the chromatographic analyses (fig. 6). The peak which occurs after $17 \mathrm{~min}$ was not completely removed by the process. This peak was not well defined when traced on the preparative

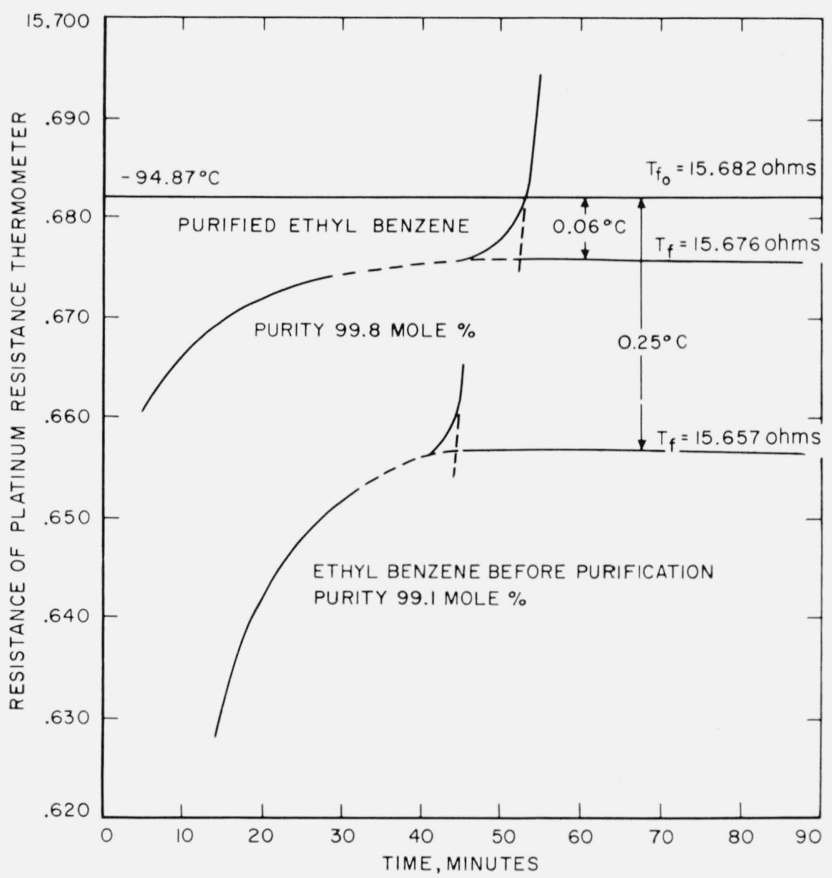

Figure 5. Melting curves of ethylbenzene before and after purification by gas chromatography.

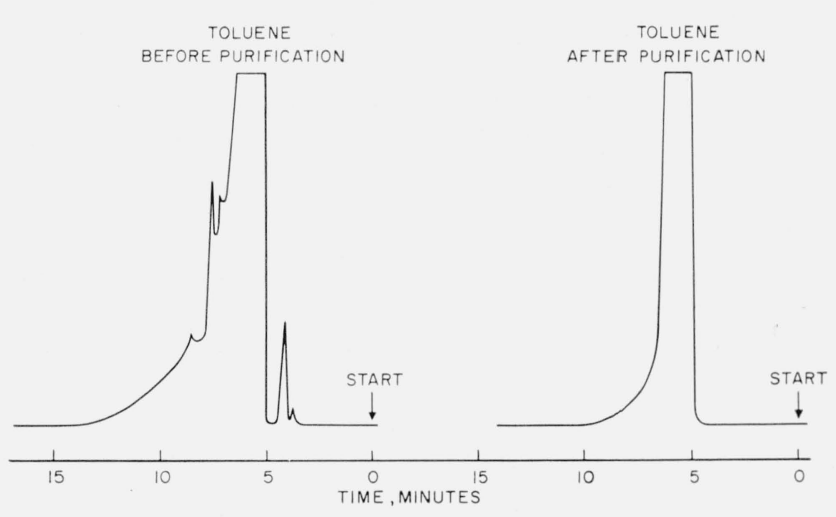

Figure 6. Chromatographic analyses of ethylbenzene before and after purification by gas chromatography.

Conditions of analysis same as in figure 4 . 


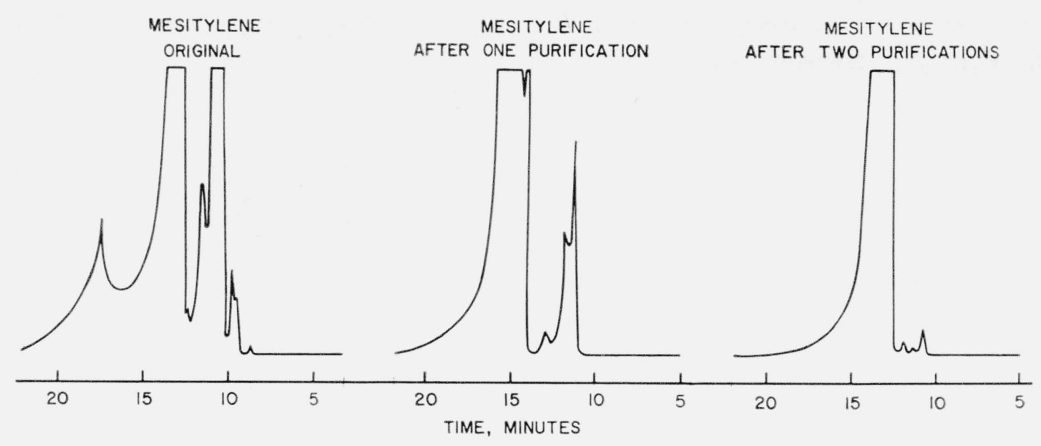

FigurE 7. Chromatographic analyses of mesitylene before and after purification by gas chromatography.

Conditions of analysis same as in figure 4.

scale recorder. It was broad and flat and may have built up an elution background thereby contaminating the major component. If a higher purity were desired, the product could be rerun through the apparatus, or further investigation done to find a more effective column or substrate.

\subsection{Purification of Mesitylene}

A chromatographic analysis of a sample of reagent grade mesitylene revealed the presence of several large peaks due to impurities. After purification with the automatic apparatus described, a similar analysis of the product indicated the purity level was increased substantially. The purified product was then reprocessed to increase its purity further. Figure 7 shows the chromatographic analyses of the original sample, the product collected after the first fractionation, and the final product obtained after the second fractionation. The large amount of impurity with an elution time close to that of mesitylene made this a difficult separation under the conditions used. In an attempt to reduce the superposition of peaks during purification, the amount of mesitylene charged into the column was adjusted to only $0.1 \mathrm{ml}$ every $20 \mathrm{~min}$. It is apparent that even the smaller charge did not entirely eliminate this difficulty.

\subsection{Improvements in the Apparatus}

After the purifications just described, the activating switch at the end of the scale was removed, and replaced by a variable-cam operated switch mounted on a shaft at the center of the large gear that controls the position of the pen carriage. Thus one may start and stop collection of purified material at any point on the scale by adjustment of the cam opening and its rotary position. This improvement allows the entire chromatogram, when properly attenuated, to be presented on the chart, and makes possible a better selection of the collection time. A larger portion of the impurities represented as "shoulders" on the main peak may thereby be rejected.

\section{Conclusion}

An apparatus has been developed for fully automatic purification of materials by gas-liquid chromatography. With the column used, toluene was purified to a high degree, but mesitylene was not so effectively separated from its impurities. It is believed that the method has much wider adaptability than described herein. By appropriate changes in the column variables involved, the process could undoubtedly be improved in efficiency and versatility.

The authors gratefully acknowledge the assistance of Herbert B. Lowey, instrument maker, who fabricated some of the parts of this apparatus.

\section{References}

[1] D. Ambrose and R. R. Collerson, Nature 17\%, 323 (1956). [2] E. P. Atkinson and G.A.P. Tuey, Gas chromatography, 270 (Butterworths, London, 1958).

[3] E. Heilbrouner, E. Kovats, and W. Simon, Helv Chim. Acta 40, 2410 (1957).

[4] J. Houmeijer, A. Kovantes, and F. van de Cratts, Gas chromatography, (Butterworths, London, 1958).

[5] A. R. Glasgow and M. Tenenbaum, Anal. Chem 28, 1907 (1956).

[6] G. S. Ross and H. D. Dixon, J. Research NBS 64C, No. 4, 271 (Oct.-Dec. 1960).

[7] C. P. Saylor, Anal. Chim Acta 17, No. 1 (1957).

(Paper 66A3-160) 